\title{
The New Virtual Crackdown on Sex Workers' Rights: Perspectives from the United States
}

\author{
Meghan Peterson, Bella Robinson, and Elena Shib
}

Suggested citation: M Peterson, B Robinson, and E Shih, 'The New Virtual Crackdown on Sex Workers' Rights: Perspectives from the United States', Anti-Trafficking Review, issue 12, 2019, pp. 189-193, www.antitraffickingreview.org

On 11 April 2018, the Fight Online Sex Trafficking Act (FOSTA) was signed into law in the United States. ${ }^{1}$ FOSTA introduced new provisions to amend the Communications Act of 1934 so that websites can be prosecuted if they engage 'in the promotion or facilitation of prostitution' or 'facilitate traffickers in advertising the sale of unlawful sex acts with sex trafficking victims. ${ }^{2}$ While supporters of the law claim that its aim is to target human traffickers, its text makes no effort to differentiate between trafficking and consensual sex work and it functionally includes websites where workers advertise services or share information, including safety tips. ${ }^{3}$ Following the law's passage_and even before its full implementation-sex workers felt its impact as websites began to eliminate platforms previously used to advertise services. Backpage, an adult advertising website, was pre-emptively seized by the FBI. ${ }^{4}$ Other platforms began to censor or remove content related to sex work, including Google, Craigslist, and many online advertising networks. ${ }^{5}$ Sex workers in the United States have denounced the passage of FOSTA for reducing workers' ability to

1 US Congress, Allow States and Victims to Fight Online Sex Trafficking Act (FOSTA) of 2017.

2 Ibid.

3 Global Network of Sex Work Projects, Briefing Note: U.S.A. FOSTA Legislation, NSWP, 2018, retrieved 24 November 2018, http://www.nswp.org/sites/ nswp.org/files/fosta_briefing_note_2018.pdf.

4 S Lynch and L Lambert, 'Sex ads website Backpage shut down by U.S. authorities', Reuters, 6 April 2018, https://www.reuters.com/article/us-usa-backpagejustice/sex-ads-website-backpage-shut-down-by-u-s-authoritiesidUSKCN1HD2QP.

5 Survivors Against SESTA, 'Documenting Tech Actions', 21 March 2018, https:/ /survivorsagainstsesta.org/documentation. 
screen clients and ensure safety practices. ${ }^{6}$ This paper provides an overview of the findings of a recent survey with sex workers in the United States, details the advent of similar initiatives in other countries, and explores how the legislation conflates trafficking with consensual sex work.

\section{Effects of FOSTA}

Between the bill's passage and late 2018, FOSTA's effects had already been tangibly felt in sex worker communities. While there was no noticeable reduction in sex work, workers reported having to resort to unsafe practices. To gauge the effects of FOSTA, from 14 April to 25 May 2018, the sex workerled organisation Call Off Your Tired Old Tactics-Rhode Island chapter (COYOTE-RI) conducted an 'After FOSTA' survey. Survey questions related to income, experiences of violence and exploitation, and screening practices before and after FOSTA. The survey, which was conducted online, was distributed through social media and forwarded to sex worker advocacy organisations in the United States, which were encouraged to share links to the survey through their social media platforms. In doing so, the survey reached a wide array of sex workers. The survey results were analysed by the Sex Workers Outreach Project (SWOP) Seattle. ${ }^{7}$

Of 262 participants, 60 per cent reported that they had to take on potentially violent clients to make ends meet following the enactment of FOSTA. One of the benefits of online advertising is that it provides workers the time and ability to screen clients, for example by verifying a client's identity and reputation before agreeing to see them. The survey results, however, indicated a reduction in screening practices. 92 per cent of participants noted that before FOSTA, they had screened their clients, but for the time after FOSTA's passage, this figure dropped to 63 per cent. One participant qualitatively commented, 'I try to still screen, but sometimes I just can't because I truly need the money.' Another responded that, 'I try to, but have moved to "dating" websites that are in denial about sex work. It's much, much harder to screen since so many sex worker sites went down.'

Seventy per cent of participants in the survey also reported that they had experienced loss of income since the law's enactment. One stated that they 'stopped advertising on [Backpage] after they removed the erotic services section

6 E Witt, 'After the Closure of Backpage, Increasingly Vulnerable Sex Workers are Demanding their Rights', The New Yorker, 8 June 2018, https:// www.newyorker.com/news/dispatch/after-the-closure-of-backpageincreasingly-vulnerable-sex-workers-are-demanding-their-rights.

7 COYOTE RI, 'COYOTE-RI Impact Survey Results', 26 May 2018, retrieved 13 September 2018, https://docs.google.com/presentation/d/1KBsVBQh7 EsRexAyZacaf_fUvvsVb2MR1Q30_gV7Jegc/edit\#slide=id.p. 
last year. It was [my] main source of income at the time.' Another felt 'encouraged to engage in activities outside of [my] comfort zone because [I] need the income.' Other respondents indicated an increase in solicitations from potentially dangerous clients. For example, in response to questions about whether anyone had recently tried to exploit, threaten, or receive free services from them, 65 per cent answered affirmatively. One worker stated that 'Men calling themselves gorilla pimps [had] been trying to access all the girls since [FOSTA] passed.' Another reported similar solicitation, adding that the number of predatory requests had increased and they had met with 'more folks trying to coerce [me] into work [I] don't want to do.' Overall, survey results demonstrated decreases in income, available clients, screening practices, and worker bargaining power. Participants also reported increases in risk taking, contact from predators preying on desperation, and demands for cheaper services.

\section{International Implications}

In addition to its domestic impact, FOSTA also has the potential to influence legal regimes outside of the United States. Since the law's passage, antitrafficking and conservative groups have tried to promote similar laws in other countries. For example, Israel introduced a Swedish-style 'end demand' law, including a ban on advertisements for sex work. ${ }^{8}$ In the UK, the All-Party Parliamentary Group on Prostitution and the Global Sex Trade recommended passage of a similar-style law. ${ }^{9}$ Additionally, given the global reach of the internet, sex workers outside the United States may use or rely on American personals websites to advertise or to organise. Sex workers in Australia and New Zealand, for instance, have already noted that web-based advertising platforms they previously used have been dismantled. ${ }^{10}$ FOSTA's effects have therefore been felt beyond the United States.

8 L Yaron, 'Israel Targets the Sex Industry: Moving to Ban Internet Ads, Fine the Johns and Close Websites', Haaretz, 13 June 2018, retrieved 8 January 2019, https://www.haaretz.com/israel-news/.premium-israel-targets-sex-industrythrough-new-knesset-bill-1.6173744.

9 All-Party Parliamentary Group on Prostitution and the Global Sex Trade, Bebind Closed Doors: Organised sexual exploitation in England and Wales, retrieved 24 November 2018, https://appgprostitution.uk/wp-content/uploads/2018/05/ Behind-closed-doors-APPG-on-Prostitution.pdf.

${ }^{10}$ M Young, 'Sex workers in Australia say American law is creating devastating losses back home,' news.com.au, 23 April 2018, https://www.news.com.au/ lifestyle/relationships/sex/sex-workers-in-australia-say-american-law-iscreating-devastating-losses-back-home/news-story/09139a 2 f0d 631cd7284090d2336ca517; B Macdonald, 'How the FBI has disrupted NZ's sex work industry', NZ Herald, 23 April 2018, https://www.nzherald.co.nz/lifestyle/ news $/$ article.cfm?c_id=6\&objectid $=12037972$. 
FOSTA's passage illustrates how stakeholders such as anti-trafficking organisations, legislators, and faith-based organisations have targeted sex workers by conflating them with victims of trafficking. The discourse surrounding trafficking in the United States has applied victim narratives that strip workers of their agency. Using moralistic arguments, the prevalence of trafficking in the sex industry compared to other labour sectors has been overstated. ${ }^{11}$ The only comprehensive, evidence-based policy to protect sex workers is decriminalisation. Decriminalisation has been associated with better sex worker health and better HIV outcomes. ${ }^{12}$ Organisations dedicated to human rights and health, such as the World Health Organization, UNAIDS, and Amnesty International, have called for decriminalisation based on empirical evidence. ${ }^{13}$ As the rollout of FOSTA impacts sex workers both in the United States and globally, sex workers' rights advocates must be aware of how similar laws could further endanger workers.

Meghan Peterson is a public health researcher at Brown University's School of Public Health in Providence, Rhode Island. Her work focuses on the impacts of incarceration on public health outcomes. She is also a sex worker rights advocate and serves on the board of COYOTE Rhode Island. Email: meghan_peterson@brown.edu.

Bella Robinson is the Executive Director of COYOTE-RI and a sex worker rights activist who has worked in the sex industry for over thirty years. As the director of COYOTE-RI, builds and strengthens support networks for sex workers in Rhode Island and works in close collaboration with activists nationwide. Her personal experiences with the criminal justice system over the past four decades give her exceptional expertise in the areas of sex worker rights and human trafficking. Email: bella@coyoteri.org.

11 A Romano, 'A new law intended to curb sex trafficking threatens the future of the internet as we know it', Vox, 13 April 2018, retrieved 24 November 2018, https://www.vox.com/culture/2018/4/13/17172762/fosta-sesta-backpage230-internet-freedom.

12 C Beyrer et al., 'An action agenda for HIV and sex workers', The Lancet, vol. 385, no. 9964, 2015, pp. 287-301, https://doi.org/ 10.1016/S0140-6736(14)609338.

13 Amnesty International, 'Amnesty International publishes policy and research on protection of sex workers' rights', 26 May 2016, https://www.amnesty.org/ en/latest/news/2016/05/amnesty-international-publishes-policy-and-researchon-protection-of-sex-workers-rights/; WHO, UNFPA, UNAIDS and NSWP, Prevention and Treatment of HIV and Other Sexually Transmitted Infections for Sex Workers in Low- and Middle-Income Countries, World Health Organization, Geneva, 2012. 
Elena Shih is an Assistant Professor of American Studies and Ethnic Studies at Brown University in Rhode Island. Shih's current book project, Manufacturing Freedom: Rescue, Rebabilitation, and the Slave Free Good, is a global ethnography of the transnational social movement to combat human trafficking through ethical consumption, and market-based vocational training and rehabilitation schemes. Email: elena_shih@brown.edu. 